\title{
Efficacy of measures of hygiene in workers sensitised to acid anhydrides and the influence of selection bias on the results
}

\author{
H Drexler, K-H Schaller, J Nielsen, A Weber, $M$ Weihrauch, H Welinder, S Skerfving
}

\begin{abstract}
Objectives-Organic acid anhydrides are potential sensitisers and cause occupational airway diseases. In an intervention study the efficacy of measures of hygiene at the workplace and possible selection bias were investigated.

Methods-A first investigation with 110 workers exposed to hexahydrophthalic acid anhydride (HHPA) and methyltetrahydrophthalic acid anhydride (MTHPA) was carried out in July 1991. The results (skin prick test, specific serum IgE) showed that 20 people were sensitised, and in a challenge test the clinical relevance of the sensitisation was confirmed in six subjects. In December 1991, the hygiene conditions at the plant were improved. In November 1995 a second investigation of 84 people was performed (anamnesis, skin prick test, specific IgE, spirometry, and ambient and biological monitoring). The 27 people who had left the plant in the meantime were asked their reasons for leaving.
\end{abstract}

Results-The relative risk of people sensitised in 1991 of leaving the plant between 1991 and 1995 was 2.6 (95\% confidence interval (95\% CI) 1.4 to 4.9 ) compared with people without any sign of sensitisation. The percentage of people identified as sensitised in 1991, who were still working at the plant and came to the second investigation, was higher than for people without evidence of sensitisation $(10 / 10 v 47 / 73 ; p<0.05)$. In all the 10 sensitised people in 1991 the findings of the first investigation were confirmed in 1995. The rate of sensitisation in 1995 was $21 \%$. None of the six people employed after 1991 showed evidence of sensitisation. Of the six people with clinically relevant sensitisation confirmed by a challenge test in 1991, five were still at their workplace. From 1991 they were only exposed to MTHPA at a reduced concentration $\left(<0.5-36 \mu \mathrm{g} / \mathrm{m}^{3}\right.$ in 1995). All of them reported fewer symptoms than in 1991 . No signs of bronchial obstruction were detected by spirometry at the workplace. Conclusions-In cross sectional studies there is a selection bias with a risk of underestimating the incidence of allergic diseases. The results further suggest that the improved hygiene conditions probably had a positive effect on the symptoms in sensitised people.

(Occup Environ Med 1999;56:202-205)
Keywords: acid anhydrides; occupational asthma; selection bias; healthy worker effect

Organic acid anhydrides belong to the group of low molecular weight allergens that cause sensitisation and diseases of the eyes, the upper airways, and the lungs in exposed people. ${ }^{1}$ The prevalence of specific IgE antibodies against organic acid anhydrides in exposed workers can be $>40 \%,{ }^{23}$ but not all of these workers have symptoms. On the other hand, exposed people can have rhinitis or asthma at the workplace without having specific IgE antibodies. ${ }^{45}$ There is no doubt, however, that at least a large fraction of occupational conjunctivitis, rhinitis, and asthma in workers exposed to organic acid anhydrides is mediated by IgE. ${ }^{4-6}$ Sensitisation and the provocation of allergic symptoms are dose-related, both primary and secondary prevention can be effective, not only for avoiding classic toxic effects, but also allergies. ${ }^{7}$ This is especially true for the primary induction of allergies. It is still unclear, however, whether sensitised people with symptoms can continue their work under improved measures of hygiene. It is difficult to draw conclusions from cross sectional studies, because selection bias may be an important factor when symptoms related to the workplace exist, as is particularly the case with allergic diseases.

We therefore carried out two investigations of workers exposed to acid anhydrides in the same plant in 1991 and 1995. The investigation was carried out as an intervention study, with the aim of answering the following questions.

(1) Can the effect of improved hygienic conditions be seen in workers exposed to organic acid anhydrides?

(2) Is there a selection bias which can influence the results?

Subjects and methods

In July, 1991 a cross sectional study was performed to find out the prevalence and the clinical relevance of sensitisation in workers exposed to hexahydrophthalic anhydride (HHPA) and methyltetrahydrophthalic acid (MTHPA), used as hardeners in a plant in which epoxy resins were produced for manufacture of electrical equipment. Of the 110 people who were investigated, 20 people were identified as being sensitised (specific serum IgE against HHPA and MTHPA or a positive result in the skin prick test) and in six of these 
the clinical relevance of the sensitisation was confirmed in a challenge test.

In the year of the investigation, the results were presented to the management of the plant and as a consequence of these results, the hygiene conditions were improved. Hence, since December 1991, the epoxy resin has been made in a closed system with a modified hardener (MTHPA in a suspension with mineral compounds); HHPA is not used any more. The other conditions at the workplace have not changed and the amount of epoxy resin produced is almost the same. Unfortunately, analysis of air samples was not possible in $1991 .{ }^{5}$ In November 1995 the concentration of MTHPA in air was analysed in three personal air samples $\left(<5 \mu \mathrm{g} / \mathrm{m}^{3} ; 13 \mu \mathrm{g} / \mathrm{m}^{3}, 36 \mu \mathrm{g} / \mathrm{m}^{3}\right)$ and five stationary air samples (range $<0.5-26$ $\mu \mathrm{g} / \mathrm{m}^{3}$ (median $\left.<0.5 \mu \mathrm{g} / \mathrm{m}^{3}\right)$ ).

In November 1995, a second investigation was performed at the plant. All people who had left the plant between 1991 and 1995 were identified and asked by letter to explain why they had left and whether they had symptoms of an allergy. The number of employees at the plant had decreased from 160 people in 1991 to 134 in 1995 . On the day of investigation, 106 $(79 \%)$ people were present at their workplace and $84(63 \%)$ of them took part (47 men, 37 women, age range $23-60$ (median: 38.5$)$ years, duration of exposure 0.5-27 (median: 8.5) years). The investigations were carried out as recommended by the European Study Group on Acid Anhydrides (ESGAA). The study protocol consisted of ambient monitoring ${ }^{89}$ and biological monitoring of MTHPA through the corresponding acid in urine, a standardised questionnaire, physical examination, spirometry, and skin prick tests with six common allergens and with human serum albumin conjugates of organic acid anhydrides (HHPA, MTHPA, phthalic anhydride, methylhexahydrophthalic anhydride). Additionally a skin prick test was performed with a $5 \%$ solution of MTHPA in acetone. ${ }^{10}$ The questionnaire asked about work related symptoms - such as eye complaints, rhinitis, cough, and phlegm from the chest, wheeze and tightness in the chest, shortness of breath, and asthma. A titre of specific IgE antibodies in serum samples $>0.3 \%$ specific binding or a skin prick test reaction $>2$

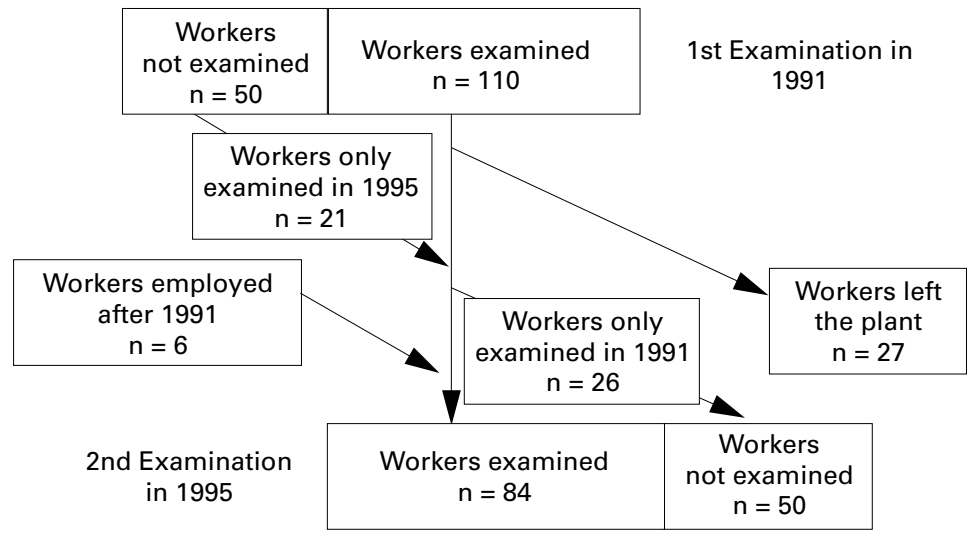

The number of people employed at the plant and their participation in the 1991 and 1995 investigations. $\mathrm{mm}$ was regarded as a sign of sensitisation. To enable comparison of the results in 1991 with those in 1995, only the results of the skin prick test with the solution in acetone were regarded here as a sign of sensitisation.

Statistical analysis was carried out with SPSS for windows. For the analysis of the different rate of participation of sensitised and not sensitised people in 1995 the Fisher's exact test was used.

\section{Results}

INFLUENCE OF SELECTION BIAS

All in all 27 people examined in 1991 had left the plant. Only 26 of these people received a letter with our questions as the address of one person examined in 1991 was unknown. Fourteen of them replied (five of them were recognised as already sensitised in 1991). Only two of them (both sensitised) said that health problems were the reason for leaving the plant, but seven (four sensitised) reported that they have fewer allergic symptoms (rhinitis, cough, shortness of breath) since leaving the plant.

Altogether 84 people took part in the investigation in 1995. Fifthy seven of them were examined for the first time during the investigation in 1991. Twenty six of the people who were examined in 1991 and who were still at the plant did not attend the second investigation. Twenty one people who were employed before July 1991 were examined in 1995 for the first time and six people had been employed at the plant after 1991 (fig 1).

Of the 27 people who had left the plant, 10 (37\%) were recognised as sensitised in 1991, and $10(12 \%)$ of the remaining 83 were also sensitised (relative risk (RR) of sensitised people leaving the plant $=2.6 ; 95 \%$ confidence interval (95\% CI) 1.4 to 4.9 ). On the other hand, all of the people recognised as sensitised in 1991 (10/ 10) came again to the second examination in 1995, whereas only 47 (64\%) of the 73 people without evidence of sensitisation in 1991 came to the second examination $(\mathrm{p}<0.05)$.

\section{SENSITISATION AND SYMPTOMS}

All positive findings in people investigated in 1991 and in 1995 are presented in table 1. Sensitisation was confirmed in all 10 people who were recognised as sensitised in 1991 and who took part in the second investigation. Of the seven people who had a positive reaction in 1991 and who were tested again in 1995 (table 1) the diameters of the wheals in the skin prick test had declined in 1995 (1991 range: 5-12 $\mathrm{mm}$, median $10 \mathrm{~mm}$, SD 2.6; 1995 range 3-12, media: $5 \mathrm{~mm}$, SD 1,8). In one case (No 63) the skin prick test was positive in 1991 and negative in 1995. In two people, specific IgE was detected in 1995 for the first time and the skin prick test was positive (Nos 42 and 70), and in another person only the skin prick test was positive for the first time in 1995 (No 104).

The positive findings in the people who were employed before 1991 and investigated in 1995 for the first time are presented in table 2 .

According to our definition of sensitisation, positive findings were found in 18 people $(21 \%$ of the people tested). All people recognised as 
Table 1 People with positive immunological findings investigated both in 1991 and 1995

\begin{tabular}{|c|c|c|c|c|c|c|c|}
\hline \multirow[b]{3}{*}{ Wor ker No } & \multicolumn{4}{|l|}{1991} & \multicolumn{3}{|l|}{1995} \\
\hline & \multicolumn{2}{|c|}{$\operatorname{IgE}(k U / l)$ against } & \multirow{2}{*}{$\begin{array}{l}\text { Skin-prick test } \\
\text { (acetone) }\end{array}$} & \multirow[b]{2}{*}{ Symptoms } & \multirow{2}{*}{$\begin{array}{l}\operatorname{IgE}(\%) \\
\text { against } \\
\text { MTHPA }\end{array}$} & \multirow{2}{*}{$\begin{array}{l}\text { Skin-prick test } \\
\text { (acetone/ HSA) }\end{array}$} & \multirow[b]{2}{*}{ Symptoms } \\
\hline & HHPA & MTHPA & & & & & \\
\hline 98 & 19.0 & 13.5 & pos. & + & 6.9 & $+/+$ & + (Better) \\
\hline 110 & No data & No data & + & + & 2.6 & $+/+$ & + (Better) \\
\hline 67 & 1.2 & 0.8 & + & + & 0.8 & $+/+$ & + (No change) \\
\hline 69 & 4.2 & 2.6 & + & + & 7.7 & $+/+$ & + (Better) \\
\hline 85 & 2.08 & 0.98 & + & + & 0.8 & $+/+$ & - \\
\hline 37 & 4.8 & 2.6 & + & - & 1.8 & $+/+$ & - \\
\hline 87 & 2.0 & 1.6 & + & - & 7.2 & $+/+$ & + (New) \\
\hline 17 & 1.16 & $<0.35$ & - & - & 1.2 & $+/+$ & - \\
\hline 7 & 1.9 & 1.3 & - & - & 1.0 & $+/-$ & - \\
\hline 63 & 0.51 & 0.44 & - & + & 0.6 & $-1-$ & - \\
\hline 42 & $<0.35$ & $<0.35$ & - & - & 0.6 & $+/+$ & $+(\mathrm{New})$ \\
\hline 70 & $<0.35$ & $<0.35$ & - & _- & 7.5 & $+/+$ & - \\
\hline 104 & $<0.35$ & $<0.35$ & - & - & 0.0 & $+/+$ & - \\
\hline
\end{tabular}

Determination of IgE: 1991, Pharmacia, Uppsala, Sweden; 1995, Department of Occupational and Environmental Medicine, Lund, Sweden. Skin prick test, acetone=acetonic solution of MTHPA. HSA=human serum albumin conjugates of MTHPA. Symptoms $+=$ work related symptoms; $-=$ no work related symptoms.

Table 2 People with positive immunological findings investigated for the first time in 1995

\begin{tabular}{llll}
\hline $\begin{array}{l}\text { IgE against } \\
\text { MTHPA (\% } \\
\text { specific binding) }\end{array}$ & $\begin{array}{l}\text { Skin prick test } \\
\text { (acetone/HSA) }\end{array}$ & Symptoms & $\begin{array}{l}\text { Year of first } \\
\text { employment }\end{array}$ \\
\hline 6.4 & $+/+$ & + & 1988 \\
22 & $+/+$ & - & 1978 \\
26 & $+/+$ & - & 1991 \\
0.7 & $-/-$ & + & 1989 \\
0.1 & $+/+$ & - & 1988 \\
\hline
\end{tabular}

Skin prick test: acetone=acetonic solution of MTHPA HSA=human serum albumin conjugates of MTHPA

sensitised were employed before the measures of hygiene were changed. None of the six people who were employed at the plant after December 1991 showed evidence of sensitisation.

The spirometric examinations showed no cases of obstructive or restrictive disturbances in ventilation. The spirometric variables (vital capacity, forced vital capacity, forced expiratory volume in one second, maximal expiratory flow at $50 \%$ and $25 \%$ of forced vital capacity) did not differ between sensitised and nonsensitised subjects. Of the six people with clinically relevant sensitisation confirmed by a challenge test in 1991, five were still at their workplace. In 1995, there were fewer work related symptoms in sensitised subjects, who complained of symptoms in 1991 (1991 two cases of shortness of breath, four cases of rhinitis; 1995 four cases of rhinitis, two subjects with no symptoms). Two people recognised as sensitised in 1991 developed symptoms of rhinitis between 1991 and 1995 (table 1).

\section{Discussion}

There is no valid threshold limit value (TLV) or maximum concentration at the workplace (MAK value-Maximale Arbeitsplatz Konzentration) for MTHPA. ${ }^{112}$ The concentrations in the air found at the plant are relatively low at present compared with other workplaces, ${ }^{313}$ but must have been higher in the past, when the epoxy resin was produced in an open system with pure MTHPA and HHPA as hardeners.

INFLUENCE OF SELECTION BIAS

In occupational medicine, selection due to work related symptoms is a well known problem in cross sectional field studies (healthy worker effect), and leads to a workplace population with a lower prevalence of complaints relative to the incidence of such complaints. Among the people who left the plant between 1991 and 1995, it is noticeable that the probability of a sensitised person leaving was 2.6 times higher than for a person without any sign of sensitisation. The fact that only $2 / 14$ people reported health complaints as the cause for leaving the plant, whereas $7 / 14$ people had work related symptoms which improved after the end of the exposure, suggests that in many cases, a person's health problems are only one of several reasons for leaving work, and that the subject may not always be aware of this. The selection bias found here must lead to an underestimation of the sensitisation rate in workers exposed to organic acid anhydrides in cross sectional studies.

All people who were identified as sensitised in 1991, and who were still at the plant in 1995 came again to the second examination, compared with only $64 \%$ of non-sensitised people. Exposed people, who realise that they have a health risk due to the working conditions, are obviously more motivated to take part in a medical examination. In cross sectional studies this could lead to an overestimation of registered effects, which would be greater with lower participation rates.

\section{SENSITISATION AND SYMPTOMS}

In 1995, the prevalence of sensitisation was $21 \%$ of all workers investigated and $18.5 \%$ of people investigated for the first time in 1995, nearly the same as in 1991, despite improvements in measures of hygiene. This remains unclear, however, as eight people were first diagnosed as sensitised in 1995, although all of them were employed before the hygiene measures were changed. No evidence of sensitisation was found in the six people who were employed after 1991. This may mean that the exposure was sufficiently low not to cause primary sensitisation.

In all the people sensitised in 1991, sensitisation was confirmed in 1995. One of them developed work related rhinitis between 1991 and 1995, but all of the workers who had allergic symptoms in 1991 reported an improve- 
ment in their symptoms after the hygiene measures at the workplace were changed in December 1991. Three people without evidence of sensitisation in July 1991 were identified as sensitised in 1995. The two people who reported work related symptoms for the first time in the second investigation were not able to remember whether their symptoms started before or after December 1991, so that the question of when symptoms started cannot be answered.

It is always difficult to prove the efficacy of preventive measures in medicine. It is much easier to detect diseases or positive findings in a population. If preventive measures are successful, however, their success is reflected by a lack of findings, which is much more difficult to prove. In this intervention study, the severity and number of complaints, and the lack of sensitisation in people employed after 1991 can be interpreted as showing the efficacy of primary prevention in allergic occupational rhinitis and asthma.

\section{Conclusions}

The selection bias found makes the estimation of the incidence of allergic diseases in a cross sectional population difficult. People who know about an individual health risk are probably more motivated to take part in health surveillance programmes. On the other hand the high fraction of sensitisation in those who left work between 1991 and 1995 must also be taken into account. Both effects are indices of selection bias in cross sectional studies.

The results of our intervention study show that primary prevention probably has a positive effect on allergic symptoms in people exposed to organic acid anhydrides. Although we could not find a sensitisation in any of the six people employed after 1991 it is not obvious that there is a reduced rate of sensitisation due to lower exposure.

1 Venables KM. Low molecular weight chemicals, hypersensiivity, and direct toxicity: the acid anhydrides. Br f Ind Med 1989;46:222-32.

2 Moller DR, Gallagher JS, Bernstein DI, et al. Detection of IgE-mediated respiratory sensitization in workers exposed to hexahydrophthalic anhydride. $\mathcal{F}$ Allergy Clin Immunol 1985;75:663-72.

3 Nielsen J, Welinder H, Horstmann V, et al. Allergy to methyltetrahydrophthalic anhydride in epoxy resin workers. $\mathrm{Br} \mathcal{F}$ Ind Med 1992;49:769-75.

4 Baur X, Czuppon AB, Rauluk I, et al. A clinical and immunological study on 92 workers occupationally exposed to anhydrides. Int Arch Occup Environ Health 995;67:395-403.

5 Drexler H, Weber A, Letzel S, et al. Detection and clinical relevance of a type I allergy with occupational exposure to hexahydrophthalic anhydride and methyltetrahydrophthalic anhydride. Int Arch Occup Envir Health 1994;65:27983.

6 Nielsen $\mathrm{J}$, Welinder $\mathrm{H}$, Ottosson $\mathrm{H}$, et al. Nasal challenge shows pathogenic relevance of specific IgE serum antibodies for nasal symptoms caused by hexahydrophthalic anhydride. Clin Exp Allergy 1994;24:440-9.

7 Venables K M. Prevention of occupational asthma. Eur Respir F 1994;7:768-78.

8 Jönsson BAG, Lindh CH, Gustavsson C, et al. Determination of cyclic organic acid anhydride in air using gas cromatography. Part 2. Sampling and determination of hexahydrophthalic anhydride, methyltetrahydrophthalic anhdride, tetrahydrophthalic anhydride and octenylsuccinic anhydride. Analyst 1996;121:1285-90.

9 Welinder H, Gustavsson C. Methyltetrahydrophthalic anhydride in air-sampling and analysis. Ann Occup Hyg 1992; 36:189-97.

10 Drexler H, Schaller KH, Weber A, et al. Skin prick test with solutions of acid anhydrides in acetone. International Archives of Allergy and Applied Immunology 1993;100:251-5.

11 American Conference of Governmental Industrial Hygienists. Threshold limit values and biological exposure indices 1995-6. Cincinnati: ACGIH, 1995.

12 DFG (Deutsche Forschungsgemeinschaft). Maximale Arbeitsplatzkonzentrationen und biologische Arbeitsstofftoleranzwerte, Mitteilung 34, Senatskommission zur Prüfung gesundheitsschädlicher Arbeitsstoffe. Weinheim: VCH Verlagsgesellschaft, 1998.

13 Welinder H, Nielsen J, Gustavsson C, et al. Specific antibodies to methyltetrahydrophthalic anhydride in exposed workers. Clin Exp Allergy 1990;20:639-45.

\section{Rejected manuscripts}

From February 1994, authors whose submitted articles are rejected will be advised of the decision and one copy of the article, together with any reviewer's comments, will be returned to them. The fournal will destroy remaining copies of the article but correspondence and reviewers' comments will be kept. 